\title{
Acción colectiva e intervención profesional del Trabajo Social: límites y posibilidades para la construcción de ciudadanía
}

\author{
Ação coletiva e intervenção profissional do \\ Serviço Social: limites e possibilidades para a \\ construção da cidadania
}

\section{Collective action and professional intervention of Social Work: limits and possibilities for the construction of citizenship}

\section{esumen}

La presente discusión busca desarrollar algunas ideas generadoras en torno al papel que la profesión de trabajador y trabajadora social ha asumido históricamente en la construcción de ciudadanía y en la conformación de un proyecto social inclusivo, justo y democrático que responda a la promoción y disfrute pleno de los derechos humanos. Para tal efecto, este documento articula cuatro discusiones básicas: en primera instancia, la naturaleza de la participación social expresada en movimientos sociales y acción colectiva; la relevancia que se le ha asignado a la participación social en el marco de la praxis de la profesión; la necesidad de repensar el proyecto de sociedad no solo desde el Trabajo Social sino en conjunción con otros actores sociales; y finalmente, un punteo de acciones locales que se enmarcan en una lógica de acciones internacionales que respaldan la idea de una construcción de ciudadanía con una dimensión globalizadora no neoliberal.

Palabras clave: Trabajo Social, movimientos sociales, acción colectiva, participación, ciudadanía.

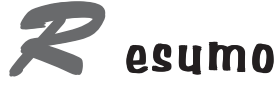

A presente discussão busca desenvolver algumas idéias fomentadoras sobre o papel que a profissão de assistente social assumiu historicamente na construção da cidadania e na configuração de um projeto social inclusivo, justo e democrático, que responda à promoção e ao pleno gozo dos direitos humanos. Para isso, este documento articula quatro discussões básicas: a natureza da participação social expressa em movimentos sociais e em ação coletiva; a relevância que se outorgou à participação social no marco da práxis da profissão; a necessidade de repensar o projeto de sociedade não somente a partir do Serviço Social, mas com a participação de outros atores sociais; e, finalmente, uma série de ações locais enquadradas em uma lógica de ações internacionais que respaldam a idéia de uma construção de cidadania com uma dimensão globalizadora não neoliberal.

Palavras-chave: Serviço Social, movimentos sociais, ação coletiva, participação, cidadania.

\section{Marcos Chinchilla Montes}

Licenciado en Trabajo Social.

Maestrando en Ciencias Políticas, Universidad de Costa Rica-UCR

Profesor de la Escuela de Trabajo Social de la UCR.

Documento elaborado en el marco del $I$ Encuentro Latinoamericano de Trabajo Social. El Trabajo Social crítico en el contexto latinoamericano, propuestas alternativas para la construcción de una nueva sociedad. Colombia, 2005.

\section{bstract}

This paper presents some ideas about the historic role of the social work profession in the construction of citizenship and in the formation of inclusionary, just and democratic policies that respond to the promotion and full benefit of human rights. The paper articulates four basic discussions. First, it looks at the nature of social participation expressed in social movements and collective action. Second, it examines the importance given to social participation in the professional praxis and thirdly the need to reconsider the social project not only from the perspective of social workers but also in conjunction with other social actors. In conclusion, the paper analyzes a series of local actions that are related to a logic of international actions that support the concept of a construction of citizenship with a globalizing dimension that is not neoliberal.

Key words: Social Work, social movements, collective action, participation, citizenship. 


\section{Movimientos sociales, acción colectiva y participación social}

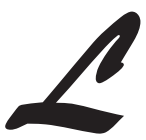

a historia de la humanidad reconoce en la libertad, la independencia, la autonomía de la persona y el derecho a la vida ${ }^{1}$ valores fundamentales. Estos se han entremezclado con otros valores hasta conformar no solo la doctrina de los derechos humanos, sino su misma práctica y constante defensa.

Las guerras contra los imperios, las luchas sociales por la independencia, la Revolución Francesa, las revueltas sociales, las luchas de los trabajadores y el esfuerzo sostenido de diversos grupos por abolir la esclavitud entre tantas otras acciones políticas, son una clara muestra tanto del deseo de emancipación como por exigir el respeto de los derechos humanos de la persona.

Este esfuerzo emancipador tiene una de sus principales expresiones en la modernidad, periodo histórico en que se plantea incluso la emancipación del ser humano en relación con un conjunto de tradiciones y valores sociales que le ataban al oscurantismo, los mitos y la metafísica. La libertad del ser humano se daría en función del dominio de la naturaleza por medio de la racionalidad científica. La ciencia permitiría superar el irracionalismo y la ignorancia, fomentando así la ansiada libertad del ser humano (ROZAS, 1988).

Durante este periodo histórico de la humanidad también surge el Estado, entendido éste como la estructura de organización funcional y política, de representación social, y particularmente, de organización social que articula y perpetúa un modelo de producción económica sobre la que descansa la sociedad.

En el caso particular de las sociedades occidentales, el Estado capitalista viene no solo a organizar la producción económica, sino también a garantizar y legitimar este modelo económico.

El capitalismo logra reproducirse desarrollando un conjunto de relaciones de producción que implican la explotación del trabajo (o sea, de las personas que venden su fuerza de trabajo como mano de obra) y la distribución inequitativa de la riqueza socialmente producida ${ }^{2}$, lo que deviene en la configuración de una cuestión social ${ }^{3}$ que genera una tensión social que históricamente en el capitalismo ha generado diferentes expresiones de enfrentamiento, participación y movilización social.

Queremos insistir en que la participación y movilización social no son un fenómeno que se dé exclusivamente en el capitalismo, como lo indicamos al inicio de este documento, a lo largo de la historia se han presentando múltiples expresiones sociales que hacen de la participación y movilización un medio para lograr libertad y reconocimiento de derechos (entre ellos pueden reconocerse las revueltas indígenas, las luchas de liberación de los esclavos, los enfrentamientos de los ha- bitantes de Cartago contra el imperio Romano). Sin embargo, en el marco del capitalismo, participación y movilización social adquieren connotaciones particulares que se asocian con la naturaleza de los grupos que la asumen y las demandas sociales que representan.

En las primeras fases del capitalismo, las mayores muestras de participación social tenían una connotación exclusivamente de lucha de clases $^{4}$. Sin embargo, en la actualidad otras propuestas teóricas sugieren ampliar la comprensión de la participación social.

Una primera discusión la desarrolla Camacho (1987) cuando identifica en los movimientos sociales una forma de expresión de tensiones en el marco de la sociedad civil. El propósito básico de estos radica en el reconocimiento por parte del Estado de sus demandas sociales y su posterior inclusión en políticas públicas.

Los movimientos sociales son un amplio paraguas de acción social en que se enfrentan intereses hegemónicos e intereses populares, de ahí la necesidad de diferenciar entre los movimientos populares y los de la clase dominante. Para este autor, los movimientos sociales están determinados por la categoría clase social y su relación con la exigencia de un proyecto político de sociedad, el cual está diferenciado según los intereses de cada una de las clases sociales.

Propone dos clasificaciones de movimientos sociales; por un lado las clasistas y pluriclasistas ${ }^{5}$; por otro, los movimientos tradicionales y los nuevos movimientos sociales. Pero en general, todos lo entienden como la expresión de las contradicciones del sistema capitalista que no puede atender todas las demandas de la sociedad.

La supuesta novedad de los movimientos sociales es cuestionada por Gunder y Fuentes (1989), y afirman que los nuevos movimientos realmente "[...] no son nuevos, así tengan ciertas características que sí lo son [...]" aunque identifican movimientos sociales que sí son nuevos como los ecologistas y los pacifistas. No obstante estas condiciones, los movimientos sociales que son agentes de resistencia y transformación social dadas las acciones de presión y propuesta que desarrollan en el plano político, en muy pocos casos representan una genuina posición de ruptura con el sistema productivo y político.

La diversidad de posibles clasificaciones teóricas sobre el origen y naturaleza de los movimientos sociales aluden a su nivel de organicidad, constancia política y a su capacidad de acción a lo largo del tiempo. Según esta propuesta, un movimiento se constituye como tal en la medida en que sea orgánico y tenga una duración en el tiempo. Desde esa perspectiva muchas expresiones de participación social quedan descalificadas como movimiento social dado que aparecen, desaparecen, se transforman o reaparecen sin ninguna otra condición más que la necesidad de articularse socialmente para dar respuesta a una necesidad social muy puntual. Esta 
situación obliga a intentar comprender las expresiones de participación social desde un marco conceptual más amplio e inclusivo.

Justamente en esa línea Garretón (2002) opta por utilizar la categoría "acción colectiva" que permite incorporar tanto las manifestaciones organizativas y reivindicativas gestadas por los movimientos sociales (sean populares o burgueses) como acciones de menor cobertura geográfica, organizativa o política que también se dan en la sociedad.

Para este autor, cada tipo societal se corresponde con formas diferentes de participación social. Por lo menos hasta finales de los años 70 del siglo pasado, los partidos políticos y diversas organizaciones obreras o campesinas eran capaces de canalizar y atender de forma "legítima" las demandas de diversos grupos sociales. En ese sentido, estas organizaciones se constituían en una válvula que regulaba las diferentes presiones sociales y limitaba cualquier iniciativa de transformación social que resultara amenazante para el sistema.

La crisis de los 80 y el esfuerzo neoliberal por reducir el Estado de Bienestar -regulador por excelencia de esas presiones- coincide tanto con el afán por generar un sentimiento colectivo de individualidad ${ }^{6}$, como con la deslegitimación y persecución de los sectores sociales sindicatos y grupos campesinos- que se oponían al modelo neoliberal y al cuestionamiento ${ }^{7}$ a la capacidad de representatividad de los partidos políticos.

En este contexto, las diferentes organizaciones sociales populares deben repensarse, reorganizarse y enfrentarse a otras manifestaciones de participación social que toman fuerza y que si bien no siempre comparten las características aludidas anteriormente a los movimientos sociales, tienen un peso importante en generar espacios reivindicativos derivado de la cuestión social.

La "acción colectiva" resulta por lo tanto no solo en un concepto más inclusivo analíticamente, reconoce que nuevos actores sociales se empoderan y generan espacios de participación ciudadana mas democráticos y con mayor presencia a nivel regional, nacional o continental. La argumentación de Hopenhayn (1988, p. 21) tiene plena relevancia en esta argumentación teórica: la participación social busca potenciar todas las capacidades del ser humano y generar protagonismo de la persona en tanto ser social. La participación social buscará por lo tanto fomentar condiciones para generar una participación plena en la toma de decisiones, en la construcción de proyectos personales y colectivos que generen inclusión social, igualdad y justicia. En suma, las diferentes manifestaciones de acción colectiva generan ciudadanía, se orientan al reconocimiento, respeto, promoción y disfrute pleno de los derechos que tiene la persona.

Desde la acción colectiva, los sectores populares enfrentan, cuestionan y posicionan sus intereses en contraposición con los de las clases dominantes. Esta tensión, inacabada, se traduce en espacios de participación social en los que se definen políticas públicas, se reconfiguran espacios de poder y se perpetúa la reproducción capitalista; en algunos casos, con significativos avances en materia de inclusión social y participación social.

Los aportes de estos autores no hacen más que recordarnos que sigue existiendo una preocupación social por generar condiciones de participación y exigibilidad de derechos, mismas que tienden a ampliarse en temas tan sensibles para la sobrevivencia humana -y del mismo planeta- como el medio ambiente y la ausencia de conflictos militares, ambos asociados con el modelo de producción capitalista.

\section{Participación social y Trabajo Social}

Uno de los principales legados del positivismo como corriente de pensamiento es el supuesto carácter de neutralidad que debe asumir la ciencia y las diferentes profesiones que hacen ciencia. La realidad social que se estudia se puede describir y explicar, se pueden identificar las "leyes" que predicen supuestos comportamientos sociales, pero bajo ninguna circunstancia se puede tomar partido para cambiar esa sociedad. La sociedad es inmutable, inamovible, no se pueden esperar cambios de ninguna naturaleza, menos inducirlos.

La génesis del Trabajo Social como profesión se asocia con esa condición de neutralidad: una profesión y disciplina que podía intervenir en las manifestaciones perversas de la cuestión social, pero que no se cuestionaba sobre la necesidad de transformar estructuralmente las condiciones que la generaban. Esta situación es similar para la mayoría de las profesiones -incluyendo las que conforman las Ciencias Sociales- y ponen en evidencia la intencionalidad burguesa por restringir cualquier esfuerzo social que adverse el control social, económico, ideológico, militar y político que detentan.

Desde ese marco de actuación profesional se desarrolló el Trabajo Social por muchas décadas, fuera en Europa, Estados Unidos de América o en América Latina. Sin embargo, ya para mediados de los años 60 del siglo XX, diversos sectores profesionales, particularmente en el cono sur, impulsaban un debate y práctica profesional orientando no solo a combatir la supuesta neutralidad de la ciencia y el Trabajo Social, sino su articulación política en la construcción de un proyecto de sociedad inclusiva, justa, democrática y respetuosa de los derechos humanos de la persona. El movimiento reconceptualizador le da nuevos bríos al Trabajo Social y particularmente, la determinación de atender las necesidades de los sectores sociales buscando su promoción social, su empoderamiento social y su identificación como sujetos históricos capaces de construir la sociedad que desean. 
El Trabajo Social dejará de concebirse como neutro ante la realidad y los problemas sociales que busca atender, se orientará a entenderse como un actor político que participa en la configuración de relaciones de poder entre sectores populares y dominantes, en su distribución y en la creación de espacios de partición social que justamente garanticen la inclusión de los sectores populares en el proceso de toma de decisiones, atención de la cuestión social y definición de un proyecto social con naturaleza colectiva.

Trabajos como los de Rene Dupont ${ }^{8}$ (1982) permiten advertir que la reconceptualización del Trabajo Social no puede entenderse solo como un cuestionamiento y revisión interna de la profesión, si fuera de esta forma, se daría un salto en materia de métodos, inclusión de teoría y formas de intervención, pero ante una realidad que no puede ser transformada. El verdadero salto de la reconceptualización consiste precisamente en la certeza de que la sociedad puede ser cambiada, que las condiciones estructurales que generan pobreza y exclusión social pueden ser modificadas y hasta incluso superadas y que el Trabajo Social puede desarrollar actividades de conocimiento y de intervención profesional orientadas a la superación de la pobreza y la exclusión social con la participación activa de los sectores populares y los sectores más progresistas de la sociedad.

Sin embargo, esta propuesta enfrentó, enfrenta y seguirá enfrentado adversarios que cuestionan la articulación entre Trabajo Social, sectores populares y progresistas y transformaciones sociales por parte de los sectores más reaccionarios de la sociedad (NETTO, 2005). Para estos sectores la intervención profesional debe limitarse a atender las manifestaciones de la cuestión social de forma técnica, pero bajo ninguna circunstancia, transformar las condiciones que generan pobreza, exclusión social y violación de los derechos humanos. Menos, construir ciudadanía en los sectores sociales.

En términos generales, encontramos dos grandes líneas de acción profesional asociadas con el tema de la participación y la construcción de ciudadanía (CHINCHILLA, 2002), a saber:

\subsection{La participación formal}

Se teje un discurso en el que se exalta la participación pero en el fondo se la condiciona, sea por medio de acciones asistencialistas, individualistas o por políticas sociales que solo contemplan la participación de las profesionales encargadas de ejecutar los proyectos sociales. Generalmente se habla de usuarios, clientes, pero nunca de ciudadanos sujetos de derechos.

La práctica profesional se caracteriza por intervenciones asistencialistas, participando en la ejecución de políticas sociales directivas, antidemocráticas y rechazando cualquier clase de asomo participativo por parte de las comunidades y grupos con los que desarrollaba su práctica profesional. No hay esfuerzos para estimular el empoderamiento y organización social.

La ejecución de estas políticas ha topado con la benevolencia, falta de criticidad o complicidad de los profesionales ${ }^{9}$ que optan por no trascender los lineamientos que brindan las instituciones y organizaciones contratantes de sus servicios.

De esta forma, nos enfrentamos a un Trabajo Social asistencialista, acrítico, apolítico y domesticado, dedicado estrictamente a operacionalizar elementos puntuales que le asignan. Este es un Trabajo Social básicamente instrumental, reproduciendo las condiciones de explotación capitalista, desconectado del contexto político y social.

\subsection{La participación activa}

Soy del criterio de que esta expresión de participación social es la que debe guiar nuestra intervención profesional, la misma está en consonancia con un proyecto ético social inclusivo, democrático, y respetuoso de los derechos de la persona.

La misma concibe a la persona como eje central de su desarrollo. La participación social es un proceso político que contempla conocer los problemas que afectan a la sociedad, identificar las soluciones, plantear y desarrollar acciones en torno a su solución y hasta evaluar la efectividad de las mismas. La participación social permitirá potenciar las capacidades políticas de las personas, grupos, comunidades y sociedad en general para acceder al poder político y participar activamente en la definición de un proyecto de sociedad socialmente inclusivo.

Esta expresión de participación social implica que las personas puedan hacer valer sus derechos políticos, civiles y sociales en cualquier nivel social, sea representándolos directamente o recurriendo a la desobediencia civil para garantizar su estricto respeto y cumplimiento.

Como ya lo mencionamos en este texto, es con la reconceptualización del Trabajo Social en los años 1960 y 
70, que se identifica la necesidad de avanzar en la articulación entre la profesión y la atención de las necesidades materiales, culturales y políticas de los sectores populares. El proyecto ético-político del Trabajo Social se traslapa con el proyecto de sociedad inclusivo y colectivo.

Desde esta argumentación se desarrolló una diversidad de acciones profesionales orientadas a promocionar la organización y participación social, la promoción de los movimientos sociales y la incorporación activa de trabajadores sociales formando liderando, orientando y sistematizando estos procesos. La participación social, la inclusión social, el fomento a la democracia participativa fueron parte de los grandes principios que le dieron contenido a las acciones de centros de enseñanza, colectivos profesionales y grupos estudiantiles.

La participación social activa es un proceso político, reconoce que se tiene la capacidad y potencialidad para poder participar en el ejercicio pleno del poder en diferentes instancias sociales. Siguiendo a Poulantzas (1979), el poder es relacional y se construye en las interacciones sociales entre clase dominante, sectores populares y otros grupos sociales que se mueven en el ajedrez político, y comprender esta condición les permite a los trabajadores sociales y a los sectores populares tomar conciencia que pueden influenciar y modificar las decisiones que la clase dominante toma.

El Trabajo Social no es una profesión homogénea, tampoco es ajena a los condicionamientos e intereses sociales y económicos que se presentan en la sociedad; desde ésta óptica, es factible desarrollar prácticas participativas y activas así como otras con un claro carácter desmovilizador. Yo opto por las primeras.

\section{Intervención profesional y acción colectiva}

A partir de las dos modalidades de participación social que se impulsan desde la intervención del Trabajo Social, también es factible identificar tres formas de estudiar -y por qué no, articularse- la acción colectiva y los movimientos sociales.

Es la primera vez en estas manifestaciones de participación social que un objeto de estudio puede ser descrito, teorizado, jerarquizado y analizado en función de los logros o limitaciones que tiene en la dinámica social. Como objeto de estudio, la profesión toma distancia de los movimientos sociales, solo se avoca a conocerlos científicamente y a obtener conclusiones generale ${ }^{10}$. Sin lugar a dudas, hay una indiscutible asociación con el positivismo y el precepto de neutralidad científica.

Una segunda vertiente profesional considera que el estudio de la acción colectiva es importante en función de los conocimientos que se desarrollen, sea para entender el contexto socio-político en que se desarrolla la intervención profesional, como para generar conocimientos que fortalezcan las acciones políticas de los sectores sociales que se involucran en estas acciones. Si bien se colabora con la posibilidad de fortalecer y orientar la organización colectiva, esta clase de iniciativas dan más la impresión de acciones de asesoría o consultoría que no suponen una plena articulación entre profesionales y acción colectiva. Este es un esfuerzo incompleto, y no supone una posición orgánica en función de privilegiar los intereses organizativos y reivindicativos de los sectores populares y progresistas.

La tercera vertiente tiene un norte muy claro: avanzar en la consolidación de un proyecto ético-político. El estudio de la acción colectiva no solo se centrará en las expresiones teóricas que asume, sino que incorpora la posibilidad de promover la organización popular y la articulación con la acción colectiva ${ }^{11}$. La práctica profesional del Trabajo Social realizada por estudiantes, profesores y profesionales, deja en evidencia los múltiples esfuerzos por avanzar en la consolidación de un proyecto de sociedad donde prevalezcan acciones como la inclusión social, la construcción de democracia, la construcción de ciudadanía y el pleno respeto y disfrute de los derechos humanos.

Sobre el primer componente, basta solo decir que un profundo y certero conocimiento de los enfoques explicativos de la acción colectiva, es necesario para conocer su origen, motivaciones éticas, desarrollo, politización, capacidad de negociación, posicionamiento social y sus avances y limitaciones en el marco del contexto nacional e internacional.

Promover la organización popular (el segundo componente) supone el impulso de nuevas organizaciones sociales, así como el mismo "fortalecimiento" de las ya existentes. En esa materia existe una larga y rica experiencia profesional que se manifiesta desde las prácticas académicas de las estudiantes, la intervención profesional vía instituciones públicas u organizaciones comunitarias, y la intervención profesional que se da de manera voluntaria pero orgánica de parte de algunos trabajadores sociales.

En muchos casos en las comunidades existen necesidades organizativas que se cristalizan con la intervención del trabajador social. No obstante, la intervención profesional no se orientará exclusivamente a la conformación de estas organizaciones; en un proceso democrático y participativo, facilitará condiciones para fortalecer a las organizaciones sociales nuevas o las que ya tienen un cierto camino recorrido en esta materia; el Trabajo Social permitirá identificar los proyectos de sociedad que se desean alcanzar, su articulación con otras organizaciones sociales, el estudio del contexto, el desarrollo organizacional, las formas de negociación, evaluará los alcances y limitaciones del proceso, etc. Todo esto en un proceso de acompañamiento y orientación ${ }^{12}$ 
que no es a perpetuidad, sino en el que se brindan los insumos básicos como para que la organización colectiva pueda avanzar por su cuenta en este proceso de empoderamiento político y de adición de intereses en la agenda regional o nacional.

El tercer y último componente nos posiciona como actores sociales que participamos activamente en la acción colectiva, sea en colectivos profesionales (sindicatos, asociaciones, gremios), movimientos sociales, grupos estudiantiles, grupos comunales o instancias de organización social que quizás no sean trascendentes en el tiempo, pero que tienen relevancia en contextos específicos de lucha y organización social. Indiferentemente de la modalidad organizativa de participación y representación, lo relevante radica en la participación social, en la exigencia de derechos y en la construcción de ciudadanía que se da desde la práctica del Trabajo Social.

Vale la pena entonces recordarnos que somos actores políticos, que la nuestra es una profesión política, que luchamos por construir espacios de empoderamiento que terminen conformando una sociedad inclusiva y justa.

Esta vertiente reconoce a su vez que la posibilidad de cambio social y construcción de un proyecto de sociedad inclusivo no es una exclusividad del Trabajo Social; como valor universal, en esta tarea intervienen diversas profesiones y particularmente, los sectores populares y grupos progresistas. De ahi la necesidad de entendernos y realizar esfuerzos de articulación y negociación con diferentes sectores sociales que comparten los mismos principios y convicciones.

\section{Globalización de la esperanza y la acción colectiva}

La pobreza y la exclusión social son inclusive anteriores a la cuestión social planteada por Marx, se encuentran fuertemente arraigadas en el desarrollo de la humanidad, y demuestran el afán por concentrar riqueza y poder en detrimento de las necesidades y derechos de la mayoría de la población del planeta.

Sin embargo, la pobreza y la exclusión social actuales se dan a escala planetaria. Existe un sistema económico y político organizado en función de acumular mayor riqueza sin importar cuantas personas se vean afectadas por ese modelo productivo. La globalización económica puede avanzar siempre y cuando la explotación capitalista y sus contradicciones sociales tengan un marco global, en el que también se fortalece el capital transnacional y la hegemonía de las potencias dominantes.

En este marco adverso en el que incluso muchas manifestaciones de la acción colectiva retrocedieron organizativa y combativamente ${ }^{13}$, el fin del siglo $X X$ ve posicionarse una nueva esperanza organizativa que dichosamente adquiere una dimensión global y que se combina con el agotamiento de la propuesta neoliberal.

Para Frank y Fuentes (1989) la dinámica de los movimientos sociales es cíclica y es necesario contextualizarlos en largos ciclos políticos, económicos e ideológicos que explican la importancia y relevancia de estos movimientos. En aquellos períodos donde la bonanza económica del modelo es notable decrecen los movimientos sociales (no desaparecen), pero cuando el modelo económico muestra retrocesos en la redistribución de riqueza, en la expansión de las inversiones, cuando crece la pobreza y las contradicciones sociales, tiende a darse una mayor movilización y presencia de los movimientos sociales que en los periodos previos. Justo en este contexto es necesario posicionar un conjunto de manifestaciones y reacciones sociales que toman lugar luego del levantamiento indígena de los zapatistas en México en el año 1994.

El levantamiento indígena en Chiapas se da justo el día en que México firma un tratado de libre comercio con Estados Unidos de América (EUA) y Canadá, dejando en evidencia que el México rico y opulento convive con un México pobre y excluido, lo que Gorostiaga (1996) con asombrosa precisión denomina Taiwanización y Somalización. El levantamiento zapatista se reviste de una fuerza moral y ética que impregna a amplios sectores sociales e intelectuales en todo el planeta, dejando en evidencia que los llamados logros de la globalización realmente no lo son, y que es necesario articular una nueva propuesta política tendiente a construir una sociedad solidaria y basada en el reconocimiento de los derechos de las personas.

Este esfuerzo político ha crecido considerablemente y nutrido diversas manifestaciones políticas de enorme relevancia para el continente y el planeta, entre ellas podemos citar las manifestaciones de Seattle (1999) con más de 60 mil participantes; la revuelta social contra la privatización de los servicios de electricidad y telecomunicaciones en Costa Rica (2000); el cacerolazo argentino (2001) que removió varios presidentes en menos de dos meses y que implicó la quiebra del modelo neoliberal; la consolidación del movimiento bolivariano en Venezuela luego de sucesivas elecciones y un fracasado golpe de Estado patrocinado por EUA; las frecuentes revueltas sociales en Bolivia por la privatización de los servicios de agua y por la nacionalización de los recursos energéticos, proceso aún inacabado pero que depuso dos presidentes; los levantamientos sociales en Perú y Ecuador, en este último país con un presidente depuesto y una organización social de indígenas ampliamente fortalecida; procesos políticos electorales en que la izquierda no solo se fortalece, sino que también asume el poder; el Fórum Social Mundial con una basta repercusión en todo el planeta y articulando diferentes iniciativas locales, nacionales 
y regionales por una nueva sociedad; las diversas acciones de oposición al Área de Libre Comercio de las Américas, a los Tratados de Libre Comercio, al Plan Puebla-Panamá o al Plan Colombia. Estas y otras acciones no menos relevantes, perfilan un panorama de participación y organización social que muestra importantes fortalezas y una actividad de movilización y exigencia de derechos muy significativa y esperanzadora para la región.

A esto tenemos que sumarle todas aquellas expresiones de acción colectiva que Palma (2002) denomina “asociatividad popular”. En algunos países el Estado se ha replegado, las viejas estructuras de participación social están agotadas y han perdido legitimidad en la sociedad; ante ello, las personas buscan nuevas formas de organización y participación en función de atender sus intereses y necesidades de una forma menos jerarquizada pero siempre en función de generar espacios de empoderamiento social. Entre estas expresiones se encuentran grupos de amigos que realizan trabajos comunitarios o vecinales, pequeños grupos ambientales, de mujeres que se asocian o clubes de la tercera edad donde también se realiza un esfuerzo por reivindicar sus derechos.

Esta forma de organización y participación puede no estar enfrentando de forma contundente al poder central o a las compañías transnacionales, pero sus acciones colaboran con la creación de ciudadanía y la generación de espacios sociales inclusivos.

En suma, los sectores populares y progresistas globalizan la esperanza, hacen que el lema "Otro mundo es posible" vaya perfilando con más certeza sus alcances.

Recebido em 30.12.2005.

Aprovado em 27.04.2006.

\section{Referencias}

CAMACHO, D. Movimientos sociales, algunas discusiones conceptuales. Revista de Ciencias Sociales, Universidad de Costa Rica, San José, Costa Rica, n. 37-38, sept./dic., 1987.

CHINCHILLA, M. Ciudadanía vs. ciudadanía. In: II Encuentro Latinoamericano Zona Sur. Experiencias de intervención en constitución de sujeto y ciudadanía. Chile, 2002. Disponible en $<$ http://www.ts.ucr.ac.cr/prodoc.htm>.

DUPONT, R. Teoría básica y metodología del Servicio Social. Uruguay, 1982. Disponible en $<$ http://www.ts.ucr.ac.cr/reco03.htm>.

GARRETÓN, M. A. La transformación de la acción colectiva en América Latina. Revista de la CEPAL, México, n. 76, abr. 2002.

GOROSTIAGA, X. Centroamérica 2015. Nicaragua, 1996. Disponible en <servicioskoinonia.org/relat/161.htm>.

GUNDER, A.; FUENTES, M. Diez tesis acerca de los movimientos sociales. Cuadernos de Ciencias Sociales, Costa Rica, FLACSO, n. 25,1989
HOPENHAYN, M. La participación y sus motivos. Revista Acción Crítica, Centro Latinoamericano de Trabajo Social, Perú, n. 24, 1988.

NETTO, J. P. La reconceptualización, aún camina, 40 años después. In: ALAYÓN, N. (Org.) Trabajo Social Latinoamericano. A 40 años de la reconceptualización. Argentina: Espacio Editorial, 2005. (Colección Ciencias Sociales).

PALMA, D. La asociatividad popular. Boletín Electrónico Surá, n. 76 nov., 2002. Disponible en <http://www.ts.ucr.ac.cr/ suradoc.htm>.

ROZAS, M. Una perspectiva teórico metodológica de la intervención profesional. Argentina: Espacio Editorial, 1988.

\section{Notas}

1 Sin lugar a dudas esos valores pueden resultar en extremo individualistas y hasta atomizantes del mismo ser humano. Los derechos humanos tienen un origen burgués y de ahí el acento individualista; sin embargo, el posterior desarrollo de esta doctrina reconoce que no se puede prescindir de la colectividad para potenciar el pleno disfrute de los derechos humanos, en ese sentido, el derecho a la vida no será solo existir, sino, vivir con calidad.

2 En su reproducción también influye el uso de la tecnología y utilización de los recursos medioambientales que son incorporados en el proceso productivo con muy bajo costo o sin costo alguno.

3 El tema de la cuestión social como categoría fundamental en el Trabajo Social y en la sociedad capitalista requiere toda una discusión aparte; para mayor información puede consultarse el documento de Margarita Rozas que se encuentra en las referencias.

4 Es importante mencionar que, si bien diversas luchas sociales como las indígenas también tuvieron y tienen lugar en el seno de sociedades capitalistas, estas no se dieron precisamente en función de las relaciones de explotación capitalistas.

5 En el primero ubica a obreros, campesinos y necesariamente a los grupos patronales; en el segundo, ubica a personas que no siempre comparten todas esas características, por ejemplo estudiantes, grupos de mujeres, ambientalistas.

6 El éxito, la individualidad, la competencia y la riqueza se convirtieron en valores sociales ideales en las sociedades neoliberales. Cada quien sería responsable por su seguridad, por su ingreso económico, por la atención de sus necesidades presentes y futuras. La competencia resultaba salvaje, y era necesario sobrevivir sin que importaran los demás. El sentido de colectividad se desdibujaba en la medida que el mismo Estado se reducía y transfería sus competencias sociales al sector privado. Este esquema perduró mientras algunas sociedades experimentaban una bonanza económica en la que efectivamente las personas se sentían seguras y beneficiadas por las privatizaciones y el éxito individual; sin embargo, el modelo no es sostenible y las fracturas están más que 
anunciadas: en diciembre del 2001 Argentina llega a la cima de una crisis social y económica que desembocó en el cambio de cinco presidentes y en una situación de pobreza y exclusión social nunca antes vista en ese país. Con el fracaso de la individualidad, resurgieron múltiples iniciativas colectivas para poder sobrevivir en la crisis.

7 Cuestionamiento de por sí válido ya que los partidos políticos, más que representar necesidades de todo el colectivo, se orientaron a aprovecharse de los procesos de privatización del patrimonio público. Era evidente la distancia entre el proyecto burgués y el proyecto popular.

8 Trabajadora social uruguaya y activa participante del Movimiento de Reconceptualización en los primeros años de los 70 .

9 Un peso importante en el tipo de participación que se fomenta lo tienen los centros formadores. Autores argentinos como Barreix y Diéguez insisten que diversas escuelas y Facultades de Trabajo Social tienen el propósito explicito de desmovilizar a los sectores sociales y cualquier intento organizativo. Es evidente que la misma burguesía apuesta por centros formadores (católicos, del Opus Dei, institutos profesionales, entre otros) que combatan la discusión y desarrollo de un proyecto ético-político que sea congruente con las necesidades de la sociedad en su amplio conjunto.

10 Uno de los ejemplos más comunes es la enseñanza de la organización y los movimientos sociales desde una expresión estrictamente teórica o referencial, sin fomentar el compromiso social de docentes y estudiantes.

11 Camacho (1987) menciona la existencia de un imperativo ético que está presente en la labor del científico, en sus palabras, "esa exigencia nos coloca al lado del pueblo, en su confrontación con las fuerzas sociales que lo dominan y explotan $[\ldots]$ profundamente comprometido con la tarea de recuperar la memoria colectiva de los movimientos populares $\mathrm{y}$, en consecuencia, contribuir con su desarrollo y fortalecimiento."

12 Esta propuesta de acompañamiento no parte de entendernos como expertos omniscientes de los problemas comunales y nacionales, de los problemas organizativos, de los espacios y condiciones de negociación. Nos reconoce como profesionales dispuestos a construir, avanzar y evaluarnos en conjunto con las organizaciones sociales, construyendo de forma colectiva espacios de participación social que empoderan a organizaciones, profesionales y a la sociedad en su conjunto.

13 Las dictaduras en América Latina barrieron con la organización social, la captaron o la reorientaron. Los sindicatos fueron corrompidos o desacreditados y otras organizaciones sociales fueron ignoradas o minimizadas.

\section{Marcos Chinchilla Montes}

mchinchi@fcs.ucr.ac.cr

Escuela de Trabajo Social

Universidad de Costa Rica

Sede Rodrigo Facio Brenes

San Pedro de Montes de Oca

San José, CostaRica

Apartado 2060-1000 